\title{
Sistema de traducción directa de español a LSM con reglas marcadas
}

\author{
Obdulia Pichardo-Lagunas, Luis Partida-Terrón, Bella Martínez-Seis, \\ Adriana Alvear-Gallegos, Raúl Serrano-Olea \\ Instituto Politécnico Nacional, \\ Unidad Profesional Interdisciplinaria en Ingeniería y Tecnologías Avanzadas, \\ Ciudad de México, México \\ \{opichardol, bmartinezs\}@ipn.mx, lpartidat1000@alumno.ipn.mx
}

\begin{abstract}
Resumen. La traducción automática se enfrenta a complejidades computacionales y lingüísticas; así como a los principios que rigen tanto la lengua origen como la lengua meta. Este proceso se complica aún más alguna de las lenguas involucradas no son escritas como es el caso de la Lengua de Señas Mexicana (LSM), la cual es desarrollada por personas con discapacidad auditiva. El presente trabajo se centra en el desarrollo de una herramienta para la traducción directa con reglas marcadas del español escrito a Lengua de Señas Mexicano (LSM). Para ello se hace uso de bases de datos multimedia por ser una lengua viso-gestual y de PNL para traducción automática con análisis léxico, sintáctico y morfológico.
\end{abstract}

Palabras clave: Traducción automática, sordera, procesamiento de lenguaje natural, lingüística computacional, bases de datos multimedia, LSM.

\section{System for Direct Translation from Spanish into LSM with Marked Rules}

\begin{abstract}
Automatic translation faces computational as well as linguistic complexities because of the principles and standards of the original and the target language. This process is even bigger challenge when the languages are not written, as it is the case of Mexican Sign Language (LSM), which is used by people with hearing disabilities. This paper focuses on the development of a tool for direct translation with rules; the translation is from written Spanish to Mexican Sign Language. This tool uses multimedia databases because of the visual-gestual language involved, and it uses NLP for the automatic translation with lexical, syntactic and morphological analysis.
\end{abstract}

Keywords: Automatic translation, deafness, natural language processing, computational linguistics, multimedia databases, LSM.

\section{Introducción}

La discapacidad auditiva se refiere a la falta o reducción de la habilidad para oír claramente debido a un problema en algún lugar del mecanismo auditivo [1]. El uso de 
la lengua de señas sitúa, a las personas sordas, como una comunidad lingüística minoritaria, quienes hacen uso de la lengua de señas mexicana (LSM) como medio de comunicación. Dicha lengua no tiene una relación directa con el español de México por lo que la población oyente no se puede comunicar fácilmente por escrito con la comunidad siliente.

Las personas sordas son clasificadas según su manejo del lenguaje en seis grupos [2]: el primer grupo lo conforman los monolingües que solo se expresan en LSM, el segundo los que tienen como primera lengua la LSM y como una segunda lengua el español oral y/o escrito, el tercer grupo está formado por los bilingües que además de la LSM usan alguna otra lengua de señas como la ASL, el cuarto grupo conocen la LSM y el español puede considerarse su primera lengua, en el quinto grupo habría que considerarse a los semilingües que no son competentes en la LSM ni en español y el sexto grupo lo constituyen aquellos que no han recibido educación formal y por lo tanto desconocer el español y la LSM usando como medio de comunicación señas caseras o familiares. De tal forma que la mayoría de los sordos en México enfrentan dificultades para entablar una comunicación con una persona en español.

La LSM no cuenta con un vocabulario establecido oficialmente ni con reglas gramaticales normadas, ya que en ocasiones es desarrollada de manera intuitiva por sectores de la población con discapacidad auditiva. Además, la educación de las personas sordas depende del momento en el cual perdieron la capacidad auditiva: las personas que se volvieron sordas después de haber adquirido el español no presentan un problema lingüístico, porque, en el español escrito no son diferentes a los oyentes; en cambio, las personas que perdieron la audición antes de adquirir la lengua de su comunidad, en este caso el español, pocos llegan a tener una competencia lingüística en esa lengua [14].

Las principales diferencias entre las lenguas de señas y las lenguas orales son principalmente en su estructura, ya que es ágrafa (sin escritura) y no se produce (emisión vocal) ni se percibe (atención auditiva) como las lenguas orales. La Lengua de Señas basa su funcionamiento en la percepción visual; posee su propio vocabulario y elementos llamados parámetros formacionales, que son las diferentes partes que forman un signo (por ejemplo, el movimiento de la mano, el lugar donde se hace el signo, la forma de la mano, expresión corporal) y estos, a su vez, formarán las frases signadas [12]. Cabe destacar que existen factores que provocan variaciones de la LSM, ya que no se cuenta con diccionarios de LS, hay baja capacitación y enseñanza de la misma, los carentes puntos de reunión entre personas sordas, al igual que los oyentes se utilizan términos y expresiones que identifican a un grupo personas.

La integración de grupos sociales marginados es de suma importancia, por ello es importante que las personas oyentes conozcan y aprendan la Lengua de Señas Mexicana (LSM), de esta forma se rompe la barrera de comunicación que existe entre una persona sorda y una oyente, y el distanciamiento que se genera incluso con su familia. Por lo tanto se considera pertinente el desarrollo de herramientas de apoyo para comprender y/o aprender LSM.

El sistema desarrollado proporciona funciones de análisis léxico, sintáctico y morfológico. La traducción automática se realiza del español de México escrito a la LSM, de manera que se deberá ingresar una oración en español y ésta se mostrará de forma escrita como es utilizada en el LSM, y al ser una lengua viso-gestual se desplegará el video con las señas de la frase traducida. Para realizar esto debemos 
indicar unos temas de interés los cuales se muestran en la sección de Antecedentes, en la Sección 2 está la metodología, aquí se describen las reglas para realizar la traducción además de cuestiones básicas para el funcionamiento del traductor, en la Sección 3 se muestran los resultados obtenidos con algunas frases obtenidas y finalmente en las conclusiones hacemos un análisis de lo logrado y los aspectos a mejorar.

\section{Antecedentes}

En esta sección se describen los antecedentes y elementos esenciales del procesamiento natural del lenguaje empleados, algunos conceptos de traducción directa y de la gramática usada por LSM.

El Procesamiento de Lenguaje Natural (PLN) es el reconocimiento y utilización de la información expresada en un lenguaje humano a través de sistemas informáticos [6]. Algunos tipos de análisis en PLN incluyen: el léxico, el morfológico, el sintáctico, el semántico, de discurso, entre otros; de los cuales hacemos uso de los tres primeros en este acercamiento a la traducción directa con las reglas marcadas. El análisis léxico especifica los tokens del lenguaje considerando que puede haber varios tokens que correspondan a una misma expresión regular. El problema de reconocer que una palabra, por ejemplo, en plural, digamos zapatos se puede descomponer en morfemas ("zapato" y "-s") y construir una representación estructurada de tal descomposición, se conoce como análisis morfológico. Un análisis sintáctico o parsing es la combinación del reconocimiento de una cadena (oración) de entrada con la asignación a ella de una estructura sintáctica. Se suele representar tal estructura (o derivación) mediante un árbol [6]. Sin embargo también se utiliza para la identificación de los componentes funcionales de las oraciones.

El PLN incluye a los sistemas traductores automáticos. Mediante ellos, un usuario puede leer, en su propio lenguaje, un texto escrito en otro lenguaje; o conversar, de forma escrita u oral, con otros que no comparten su misma lengua [3]. Una clasificación ya clásica de los sistemas de TA establece tres grandes grupos, los enfoques directos, los de interlingua y los de transferencia (normalmente sintáctica y en contados casos también semántica). Dichos grupos conforman la pirámide propuesta por Hutchins \& Somers [4] que se basa en las diferencias de "longitudes relativas" de los tres componentes de la traducción: análisis, transferencia y síntesis o generación.

La arquitectura directa o transformer se usa cuando no existen teorías lingüísticas formales, que se cuente con lexicones de pocas palabras para la lengua de origen y algunas decenas de reglas gramaticales para dar cuenta de los procesos de desambiguación y de reordenación del texto meta. En su forma más pura, la traducción directa conlleva la traducción palabra por palabra junto con un proceso de equivalencias de cadenas y reordenación del texto meta [5]. Los problemas inherentes a tal metodología son evidentes: el sistema no toma en consideración la estructura sintáctica de la frase ni las relaciones semánticas que existen entre las palabras [7]. Además, no existe ninguna forma de asegurar la correcta formación de las expresiones del lenguaje objeto, ya que no existen reglas gramaticales. Otra característica que limita seriamente las posibilidades de las arquitecturas transformer es la total inexistencia de una gramática de la lengua meta. 


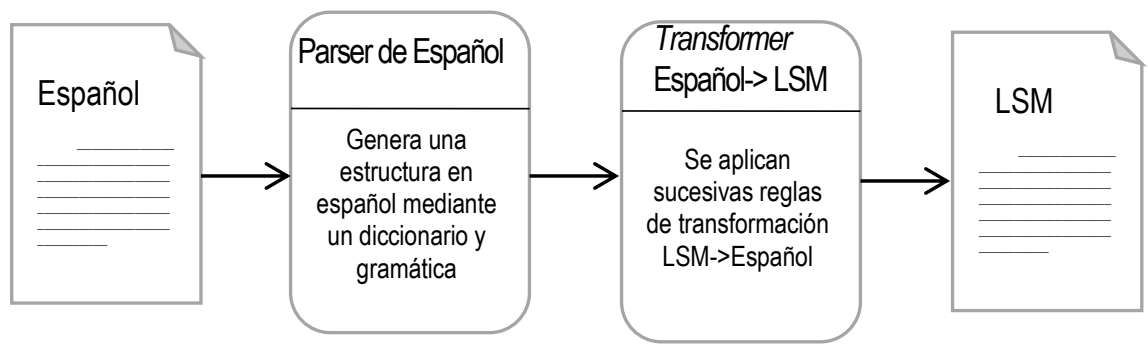

Fig. 1. Traducción Directa de español a LSM.

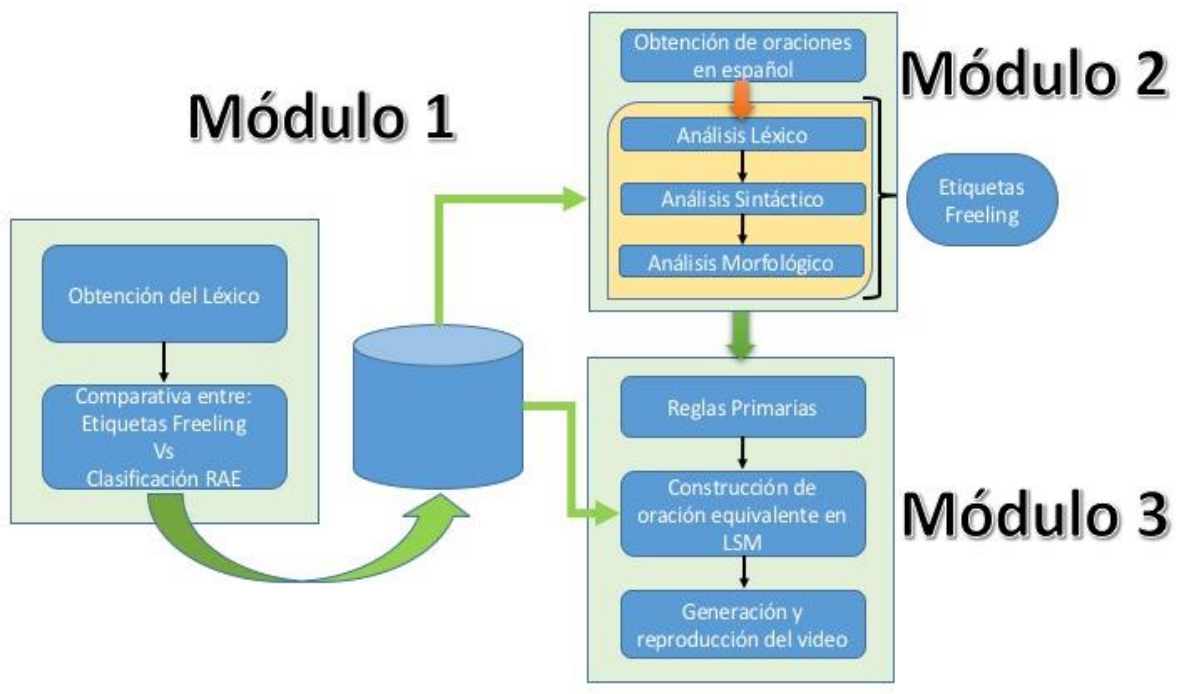

Fig. 2. Arquitectura del sistema por módulos.

La única información que el sistema posee sobre esta lengua son las reglas morfológicas de formación de palabras, además de las reglas de transformación. La Fig. 1 muestra este tipo de proceso con algunas reglas gramaticales añadidas para la traducción español-inglés.

La traducción automática de forma directa es útil en este caso de estudio debido a la falta de normas en LSM. Existen trabajos que han estudiado y propuesto estructuras gramaticales. Andy Eautough [8] quién presenta un panorama general sobre la gramática de la LSM ofreciendo varios aspectos sobre la sintaxis como el sistema pronominal, la negación, oraciones simples y complejas. Boris Fridman es un investigador que se destaca por sus aportaciones al estudio de la comunidad Sorda en México; ha investigado con mayor profundidad los verbos y estructura del lenguaje de la LSM [9]. Ha habido estudios sobre el uso del espacio con valor gramatical Hayawek [10] y la adquisición de la LSM [11]. El vocabulario en LSM tampoco está definido y se enfrenta a la variación geográfica y de lenguas con las que se relaciona, obteniendo una variación léxica. 


\section{Metodología}

El sistema es una herramienta de apoyo para una traducción directa del español a Lengua de Señas Mexicana con determinadas reglas marcadas. Se definió un determinado léxico para recabar de cada palabra la seña que es utilizada en LSM, para este punto se optó por recurrir al apoyo del Centro de Atención Integral a personas con Discapacidad de la Delegación Cuauhtémoc.

El funcionamiento del sistema se muestra en la Fig. 2, donde se aprecian los módulos que lo conforman. El Módulo 1 comprende la parte de generar muestro diccionario de palabras, el Módulo 2 es la parte donde mediante el análisis de una frase en español, se obtienen las etiquetas para su posterior uso, finalmente el Módulo 3 es la sección donde según las reglas básicas que se han determinado, se construye una oración que es equivalente a la forma en que se forman las frases en LSM, de esta nueva oración se genera el video con las señas necesarias.

\subsection{Validación de la caracterización dada por la RAE y EAGLE}

Este módulo tiene como origen la obtención del léxico, con el cual se realizó una comparación detallada de todo el vocabulario entre la clasificación de la RAE con el etiquetado Eagle.

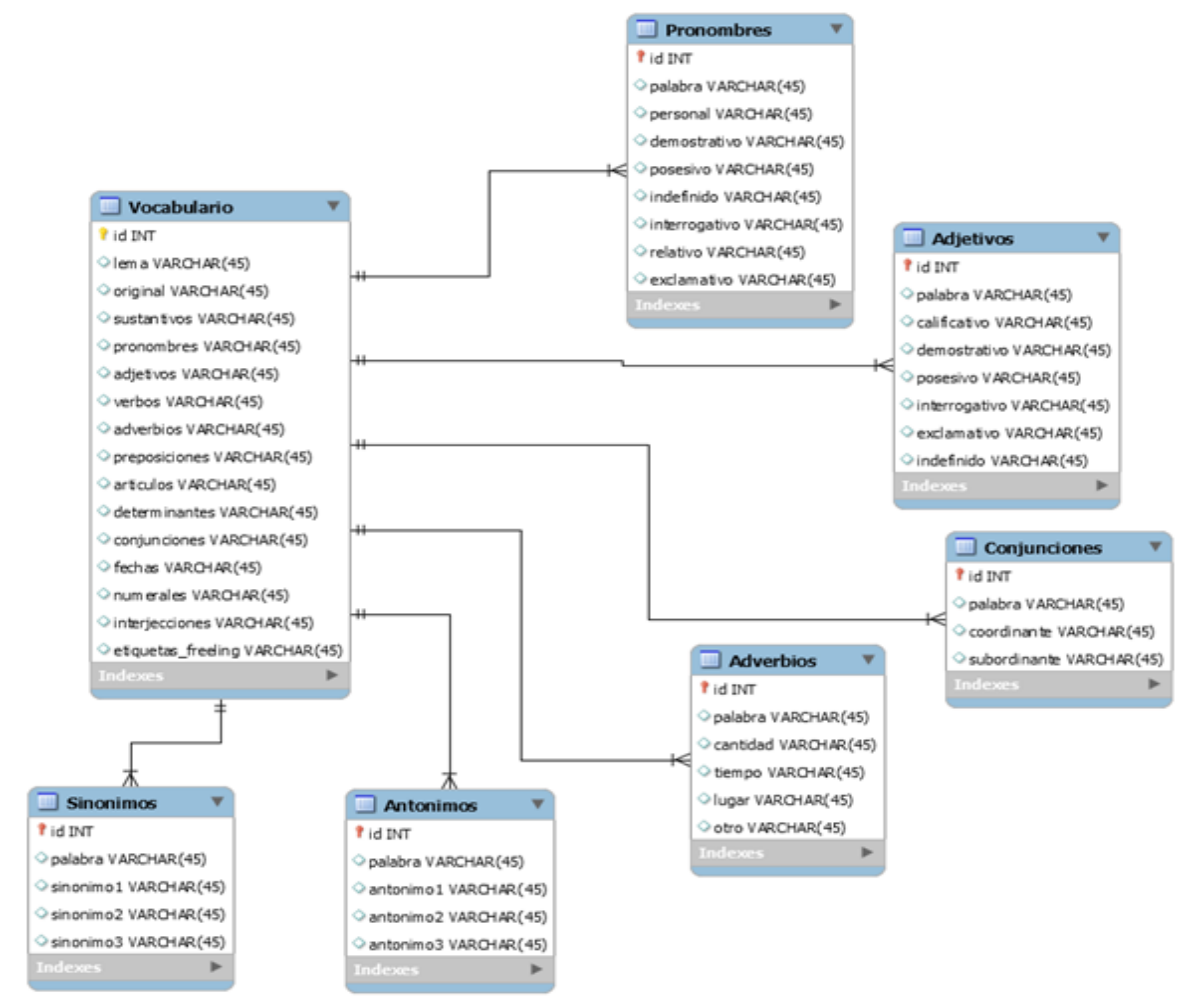

Fig. 3. Diagrama Relacional de la Base de Datos de Etiquetado. 
Obtención del léxico: se realizó una investigación del LSM para poder obtener un diccionario con la palabra en español y la grabación en video, de la seña correspondiente.

Comparativa entre etiquetado Freeling y la clasificación RAE: El analizador morfológico para el castellano utiliza un conjunto de etiquetas para representar la información morfológica de las palabras, el cual se basa en las etiquetas propuestas por el grupo EAGLES para la anotación morfosintáctica de oraciones, estas etiquetas no corresponden necesariamente a la clasificación que realiza la Real Academia Española (RAE), para las palabras. Debido a esto fue necesario hacer un etiquetado manual de nuestro diccionario, para obtener su etiqueta EAGLE y su clasificación dada por la RAE, y generar una tabla de equivalencias entre ambas. Estas equivalencias serán ocupadas más adelante para aplicar nuestras reglas de traducción.

Con esto se generó una base de datos (Ver Fig. 3), que se utilizará para buscar las palabras que se deseen traducir, este etiquetado también permite acceder a la tabla comparativa y listado de palabras por etiqueta.

Esta base de datos con el resultado de dicha comparación constituye la base para la realización de la traducción directa con reglas establecidas, las cuales serán descritas a detalle en la siguiente sección.

\subsection{Traducción directa}

Freeling proporciona funcionalidades de análisis del lenguaje, tales como:

- Tokenización texto,

- Etiquetado de roles,

- División de frases,

- El análisis morfológico

- Tratamiento sufijo, retokenización de los pronombres clíticos,

- Compuesto de reconocimiento de palabras,

- El reconocimiento de múltiples palabras flexibles,

- La predicción probabilística de categorías de palabras desconocidas,

- Codificación fonética,

- Búsqueda basada en SED de palabras similares en el diccionario

- Detección de entidades nombradas

- El reconocimiento de las fechas, números, proporciones, la moneda, y las magnitudes físicas (velocidad, peso, temperatura, densidad, etc.),

- Análisis superficial basado-Chart,

- Clasificación de una denominada sociedad,

- Anotación de sentido y desambiguación basado en WordNet,

- Análisis de dependencias basada en reglas,

- Análisis de dependencias estadística,

- Etiquetado semántico estadístico,

- Resolución de la correferencia,

- Extracción gráfico semántica.

Con el fin de implementar la gramática en forma computacional, se utilizó la herramienta Freeling, que al usarse como una biblioteca externa de nuestra aplicación 
nos sirvió principalmente para el análisis léxico (tokenización del texto y las frases ingresadas en la aplicación), análisis sintáctico (para la división de frase se identificación de elementos gramaticales en la oración) y el análisis morfológico de cada una de las palabras. Estos tres análisis son indispensables para el funcionamiento de las reglas a cumplir para la traducción.

La aplicación se desarrolló en JAVA, la cual se encarga de la conexión con el manejador de base de datos creada en MYSQL, donde se almacena la totalidad del vocabulario con sus respectivas imágenes que muestran la señal para cada palabra, la clasificación para las palabras según la RAE, el etiquetado de EAGLE para las mismas y la tabla de equivalencias.

Al no existir una gramática formal en LSM, se diseñó una forma gramatical básica para implementar en este sistema, como se muestra en la Fig. 4, que se convertirán en las reglas de traducción.

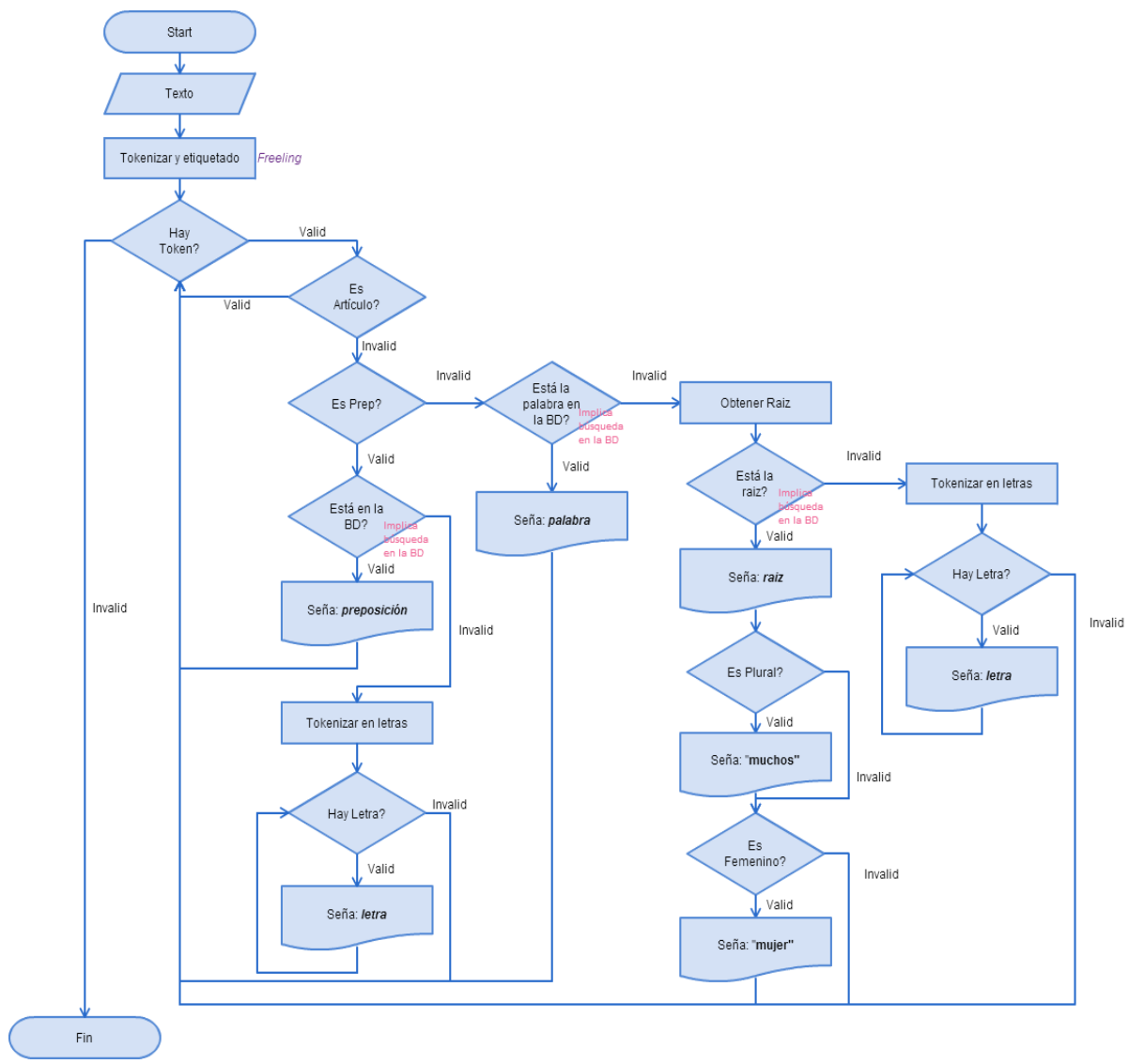

Fig. 4. Representación de la gramática básica a seguir para la traducción.

Como se aprecia en la Fig. 4. Se inicia con la captura del texto, una vez ingresada la frase a traducir, se hace la tokenización y el etiquetado de las palabras, el analizador se encarga de clasificar según su sintaxis y morfología. En el análisis sintáctico se toma en cuenta para verificar el cumplimiento de las siguientes reglas: 
1) Validación de la frase en idioma español.

2) Tokenización y etiquetado del texto.

3) División de frases para su manejo individual.

4) Los artículos se descartan debido a que en LSM no se utilizan señas para esto.

5) Las preposiciones se buscan en nuestra base de datos, si aparece esta señal será almacenada temporalmente hasta que se termine de realizar la traducción, si no se encuentra localizada en la base de datos se continúa con el proceso de deletreo de la palabra que se explicará más adelante.

6) El resto de las palabras se buscan, si se encuentra, la palabra se agrega a las lista de reproducción del video en LSM.

7) Se obtiene la raíz (lema) de la palabra, si la palabra no está en nuestro vocabulario, y se busca en determinado listado. Cabe destacar que se le agregan un par de vocablos que resultan importantes si son requeridas.

8) A las palabras en plural se le agrega la seña de "muchos".

9) A las palabras en femenino se les agrega la seña de "mujer".

10)Las palabras o lemas que no cumplan con ninguna de las reglas anteriores se deletrean.

En el análisis léxico se verifica la existencia de la palabra (regla 3, 4 y 7) o en su defecto se deletrea (Regla 10). El análisis sintáctico es empleado por si ingresó más de una frase, estas son divididas para su manejo individual, realizado en la regla 3 , además se toma en cuenta para verificar el cumplimiento de las reglas 4, 5, 6 y 7. Mientras el análisis morfológico se emplea en la regla 8, 9 y 10 para la obtención del lema y elementos de género y número. Por ejemplo, para decir, "niña", se hace la seña de "niño" más la seña de "mujer". Y en el caso de querer decir, "niñas", se referencia a las señas de "niños" + "muchos" + "mujer". Cabe mencionar que en la regla 9 y 10 se válida que palabras como madre o mamá, no se les agregue por obviedad el término de femenino, ya que, en estos casos solo se requiere de una seña para interpretar la palabra.

Por último si la palabra no cayó en ninguno de los casos anteriores no significa necesariamente que la palabra no exista en LSM, solo que debido a nuestro léxico ajustado para realizar una primera traducción en el ámbito del hogar no ha sido posible agregar un mayor número de palabras, pero si existe la posibilidad real de que la palabra verdaderamente no exista, ya que, el número de palabras existentes en esta lengua es mucho menor a las que se tienen registradas en el español. Por lo cual se procede a deletrear la raíz obtenida en el paso anterior, esta ingresa a un ciclo para separarla carácter por carácter, en donde se agregaran de forma individual a nuestra traducción final, las letras que la conformen. El deletreo en LSM es en ocasiones muy recurrido, por ejemplo, al mencionar nombres propios, marcas, palabras nuevas, o para darse a entender con personas sordas de otras regiones, donde pueden variar las señas de las palabras para un mismo objeto.

El proceso se repetirá con cada palabra que ha sido ingresada y etiquetada, si solo se ingresó una frase al terminar, se tendrá de forma escrita el resultado de la traducción. Si se ingresó más de una frase el proceso continuará hasta terminar la totalidad de las frases. Obteniendo así una traducción por cada frase.

Como se mencionó la lengua de señas basa su funcionamiento en la percepción visual, por lo que no sería un buen traductor, si no tuviera una parte visual donde se aprecie la interpretación de las señas. Por tal motivo con las traducciones obtenidas se obtienen las secuencias de las imágenes que contienen las señas, los archivos se unen 
correspondiendo a la frase traducida, y se crea un video temporal que es mostrado con la posibilidad de aumentar o disminuir la velocidad del mismo.

\subsection{Reproducción de texto traducido en Lengua de Señas}

El sistema proporcionará a cualquier usuario que tenga los conocimientos del español escrito la posibilidad de traducir frases en este idioma a lengua de señas, de esta forma puede servir como un primer acercamiento a esta lengua o para ayudar a entender la forma de aprender de las personas que se comunican mediante LSM.

Por lo cual se diseñó una interfaz de usuario, como se muestra en la Fig. 5. Las imágenes pueden variar con respecto a la última versión de la aplicación.

\section{Traductor}

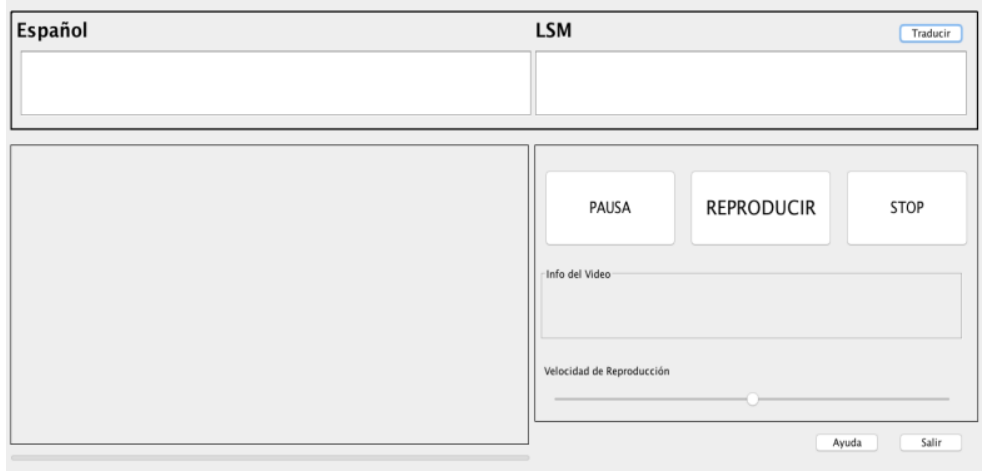

Fig. 5. Interfaz gráfica del sistema.

Como se puede apreciar la interfaz es muy intuitiva, cuenta con un área para escribir la o las frase(s) en español, mientras el área para la parte de la traducción no podrá ser modificada, además cuenta con un botón que se deberá seleccionar para comenzar la traducción. El área del rectángulo de mayor tamaño está destinada para la reproducción del video, y se podrá tener acceso a algunos controles del lado derecho de este. Como son los botones de REPRODUCIR, PAUSA y DETENER, además se cuenta con una barra para aumentar o disminuir la velocidad del video. En la sección de información del video se mostrará el número de videos (dependiendo las frases ingresadas), y cual se está reproduciendo.

Como se menciona su funcionamiento es muy intuitivo, solo se ingresa una frase a traducir en la sección de español y se presiona el botón de traducir. El programa mostrará un mensaje de traducción finalizada al concluir.

\section{$4 \quad$ Resultados}

En esta sección se muestran los resultados obtenidos en la durante la ejecución del sistema para la traducción de frases. 
Tabla 1. Ejemplos de traducción.

\begin{tabular}{|c|c|c|}
\hline Frase en español & Traducción LSM & Comentario \\
\hline El niño & Niño & Eliminación del artículo. \\
\hline Los niños & Niño muchos & $\begin{array}{l}\text { Se le agrega la seña de muchos } \\
\text { indicando el plural. }\end{array}$ \\
\hline La niña & Niño mujer & $\begin{array}{l}\text { Se ocupa la palabra raíz que se } \\
\text { tiene en la base de datos y se } \\
\text { agrega la seña de mujer, } \\
\text { indicando el femenino de la } \\
\text { palabra. }\end{array}$ \\
\hline Mi amigo Juan & Mi amigo J U A N & $\begin{array}{l}\text { La palabra que se encuentra } \\
\text { separada por espacios (JUAN), se } \\
\text { deletreará en LSM, ya que, no se } \\
\text { encontró la seña para expresar la } \\
\text { palabra, esto sucede con los } \\
\text { nombres propios. }\end{array}$ \\
\hline & & $\begin{array}{l}\text { En LSM no existen } \\
\text { conjugaciones por lo cual se } \\
\text { busca en la base de datos la raíz y }\end{array}$ \\
\hline Mi casa es grande & Mi casa estar grande & esta se muestra en la interfaz. \\
\hline
\end{tabular}

En la tabla 1 se pueden apreciar ejemplos básicos de los tipos de reglas que se siguen para la traducción. A continuación se mostrarán ejemplos más complejos donde se mezclas estos ejemplos

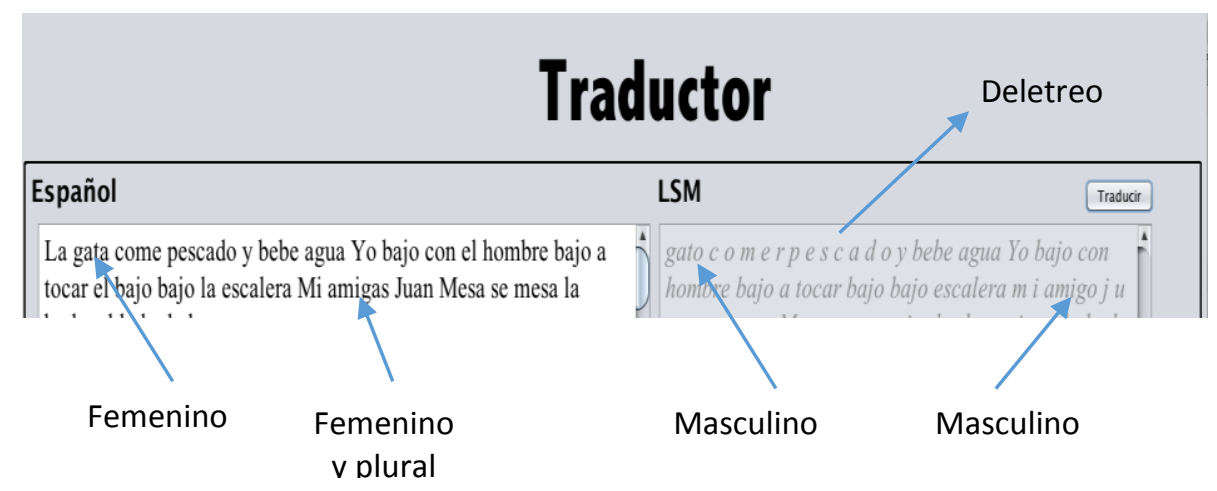

Fig. 6. Ejemplo de traducción variando género y número.

Como se muestra en la Fig. 6. Se ingresó una frase cualquiera al traductor, y esta se reescribió en la sección de LSM de la forma en que se diría, se puede apreciar como las palabras que no se han localizado en la base de datos por lo que se deletrease identifica por encontrarse en cursiva y separadas por un espacio, de este ejemplo se puede observar que aún falta léxico para una traducción completa de la frase en original, 
también es perceptible que los nombres propios siempre serán deletreados, ya que no existe seña para estos. Las palabras completas significa que han sido encontradas en la base de datos, tal cual, aparecen o el lema de la palabra basado en las reglas básicas mencionadas anteriormente. Un punto a destacar es que si no se implementara la sección de agregar la seña de mujer para femeninos y la seña de muchos para plurales, como suele hacerse en LSM, se escribirían solo los singulares y masculinos de las palabras, este ejemplo sirve para mostrar sin la implementación de esto, más adelante se mostrarán ejemplos de la traducción correcta.

Otro aspecto a resaltar es, la división de frases, se pueden ingresar varias frases y estas son analizadas independientemente de las otras.

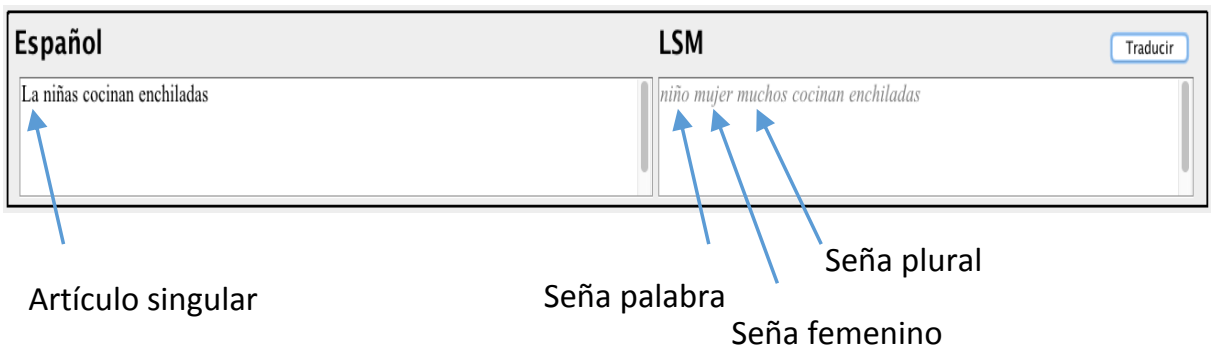

Fig. 7. Ejemplo de traducción de una frase con artículos.

En el ejemplo mostrado en la Fig. 7 se observa como al no realizarse un análisis semántico de las frases, se puede escribir "La" en lugar de "Las" y no marcará error, aunque al ser un artículo es descartado, la palabra "niñas" al ser un femenino y estar en plural, se escribe la seña del lema de la frase, más la seña de mujer, más la seña de muchos.

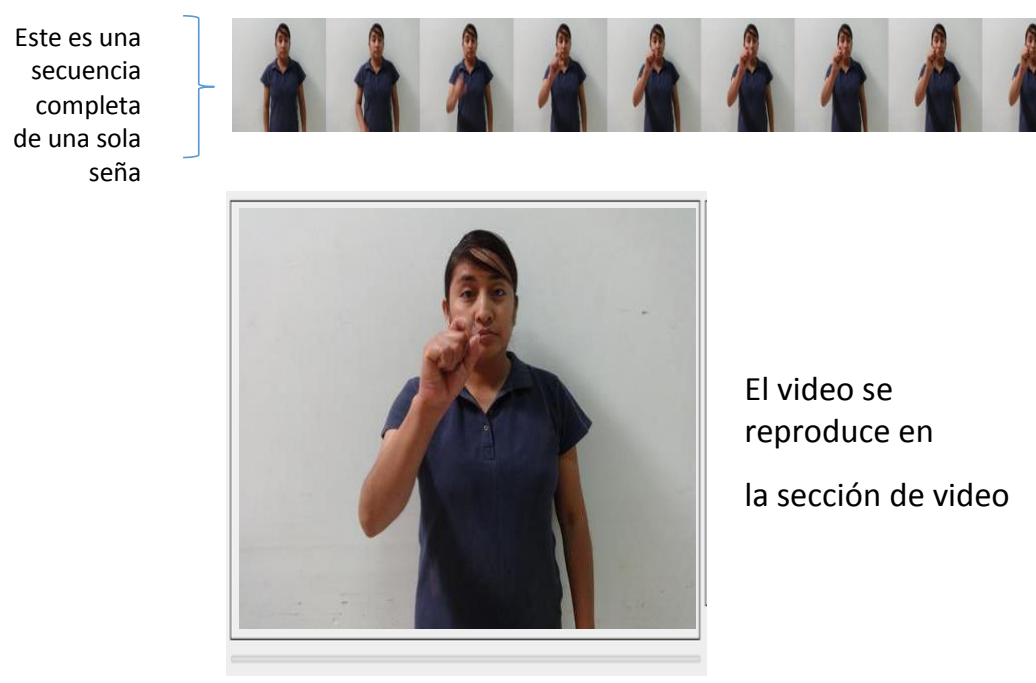

Fig. 8. Secuencia de video de una seña. 
Como se menciona las señas son reproducidas de una secuencia de 10 imágenes, para reproducir un video de una frase se agrupan las secuencias de señas como se observa en la Fig. 8.

\section{Conclusiones y trabajo a futuro}

A pesar del esfuerzo que se está realizando por parte de algunas personas y asociaciones que tratan de difundir y mejorar la práctica de la lengua de señas, aún se encuentra con muchas dificultades para su enseñanza, ya que, no se cuenta con una gramática formal e intérpretes certificados. Por lo que en la actualidad la posibilidad de contar con un traductor, pueden brindar la posibilidad de conectar las realidades de dos culturas diferentes de una forma sencilla.

El traductor automático debería ser capaz de adecuar un mensaje expresado en una lengua origen a una lengua destino, para conseguir esto el sistema presentado tiene aspectos relevantes a mejorar que se ven limitados a la falta de normatividad en LSM. Actualmente realiza una la traducción directa del texto inscrito con algunas reglas, por lo cual, se debe seguir desarrollando e investigando más la gramática de la LSM, así como trabajar en la desambiguación. Como ejemplo claro de esto es la validación sintáctica de oraciones gramaticalmente correctas, ya que aún no se han incorporado los mecanismos para realizarlos, por lo que en algunas ocasiones las oraciones, carecen de sentido, y aun así realizará la traducción basado al etiquetado que realice Freeling.

El software no garantiza la adquisición de LSM, sin embargo es una herramienta útil para adquirir las bases para dicha lengua, contribuyendo así en gran medida a la educación y compresión de personas sordas. La herramienta es un buen primer acercamiento para descubrir un mundo que para la mayoría resulta totalmente nuevo y desconocido y fomentar a través del aprendizaje de la lengua, un cambio de actitud y mayor comunicación hacia las personas sordas.

\section{Referencias}

1. Alvarado, M.: Construcción de una pedagogía para la integración. Serie: Integración Normalizada en la Formación para el Trabajo: un proceso de inclusión social de la Organización Internacional del Trabajo. Montevideo, Uruguay (1998)

2. Cruz Aldrete, M.: Gramática de la Lengua de Señas Mexicana. Doctorado. Colegio de México, Centro de Estudios Lingüísticos y Literarios (2008)

3. Gelbukh, A.: Procesamiento de Lenguaje Natural y sus Aplicaciones. En Komputer Sapiens, Vol. 1, pp. 6-11 (2010)

4. Hutchins, W.J., Somers, H.L.: An introduction to machine translation, Vol. 362, London: Academic Press (1992)

5. Moroni, Moreno Ortiz, A.: Diseño e implementación de un lexicón computacional para lexicografía y traducción automática. Estudios de lingüística del español, 9, 000-0 (2000)

6. Gelbukh, A., Sidorov, G.: Procesamiento automático del español con enfoque en recursos léxicos grandes. Dirección de Publicaciones del IPN, México (2010)

7. Trujillo, I.A.: Lexicalist Machine Translation of Spatial Prepositions. Ph.D. Dissertation. Trinity Hall, University of Cambridge (1995)

8. Lipschutz, Eatough, Andy: Mexican Sign Language Grammar. (Manuscrito inédito) (1992) 
9. Fridman Mintz, B.: Categorías verbales de aspecto y tiempo en la Lengua de Señas Mexicana. Lubbers Quesada, M., Maldonado, R. (Eds.). Dimensiones del aspecto en español, pp. 195-244, Universidad Nacional Autónoma de México. Universidad Autónoma de Querétaro (2005)

10. Hawayek, A.: El orden lineal de los objetos del verbo en la Lengua de Señas de México. Signos lingüísticos, Vol. 2, pp. 25-49, México: UAM-Iztapalapa (2005)

11. Treviño, E., Hawayek, A.: Stages in the development of grammatical space. Proceeding of the 23rd, Annual Boston University Conference on Language Development, Vol. 2, Cascadilla Press Somerville, Mass. (1999)

12. Union Nacional de Sordos. https://unsordosm.wordpress.com/lengua-de-senas/. Revisado 18 marzo 2016.

13. Pichardo-Lagunas, O., Martinez-Seis, B.: Resource Creation for Automatic Translation System from Texts in Spanish into Mexican Sign Language. Research in Computing Science, Vol. 100, pp. 129-137 (2015)

14. Radelli, B.: Una aplicación de la lingüística: la logogenia. Dimensión Antropológica, Vol. 23, septiembre-diciembre, 2001, pp. 51-72. Disponible en: http://www.dimensionantropologica.inah.gob.mx/?p=652. Revisado 18 marzo 2016 